\title{
A presença do termo juventude na produção científica da Educação Física brasileira: para onde vamos?
}

\section{RESUMO}

Este artigo procura compreender como se dá a presença do termo "juventude" na produção científica da Educação Física (EF) brasileira. Para responder a essa indagação, num primeiro momento, o texto apresenta o debate a respeito da condição juvenil, discutindo a presença dos projetos de escolarização nesse seio. Feito isso, realiza uma revisão de literatura, em termos de artigos científicos, nas principais revistas do campo da EF brasileira. A partir dos resultados, notou-se que ainda é incipiente a participação do campo científico da EF no debate sobre o conceito de juventude. Contudo, a produção do campo começa a entender que as práticas corporais e esportivas são fundamentais para a compreensão das sociabilidades juvenis, sobretudo, na constituição das múltiplas identidades dos jovens.

PALAVRAS-CHAVE: Educação física; Juventude; Pesquisa científica; Lazer; Escola

\section{Gabriel Carvalho Bungenstab}

Doutor em Sociologia pela Universidade Federal de Goiás (UFG) Universidade Estadual de Goiás UEG

Escola Superior de Educação Física e Fisioterapia (ESEFFEGO)

Goiânia, Goiás, Brasil gabrielcarv@msn.com

https://orcid.org/0000-0002-3100$\underline{1538}$ 
The presence of the term youth in the scientific production of brazilian Physical Education: where are we going?

\begin{abstract}
This article seeks to understand how the term "youth" is present in the Brazilian Physical Education (PE) scientific production. To answer this question, at first, the text presents the debate about the youth condition, discussing the presence of schooling projects in this area. Having done that, it performs a literature review, in terms of scientific articles, in the main journals in the field of Physical Education. From the results, it is noted that the participation of PE scientific field in the debate on the concept of youth is still incipient. However, the production of the field seems to understand that cultural and sports practices are fundamental for the understanding of youth sociability and for the constitution of the multiple identities of youth.
\end{abstract}

KEYWORDS: Physical education; Youth; Scientific research; Recreation; School

\author{
La presencia del término juventud en la producción científica de la Educación Física \\ brasileña: ¿hacia dónde vamos?
}

\title{
RESUMEN
}

Este artículo busca comprender cómo el término "juventud" está presente en la producción científica de Educación Física Brasileña (EF). Para responder a esta pregunta, al principio, el texto presenta el debate sobre la condición juvenil, discutiendo la presencia de proyectos escolares en esta área. Una vez hecho esto, realiza una revisión de la literatura, en términos de artículos científicos, en las principales revistas en el campo de la EF. A partir de los resultados, se observa que la participación del campo científico de la educación física en el debate sobre el concepto de juventud sigue siendo incipiente. Sin embargo, la producción del campo parece comprender que las prácticas culturales y deportivas son fundamentales para la comprensión de la sociabilidad juvenil y para la constitución de las múltiples identidades de la juventud.

PALABRAS-CLAVE: Educación física; Juventud; Investigación científica; Recreación; Escuela 


\section{INTRODUÇÃO}

Este artigo procura compreender como se dá a presença do termo "juventude" na produção científica da Educação Física (EF) brasileira. Tal empreendimento nasce a partir do trabalho de Zilberstein e Bossle (2015, p. 216) na medida em que eles objetivaram, por meio de análises de periódicos, compreender como o termo juventude aparece nos periódicos da EF e da Educação. Os autores destacam que apenas três artigos se preocuparam em conceituar o que seria juventude, salientando, também, que a maioria dos textos produzidos são oriundos de periódicos da área da Educação.

O texto de Zilberstein e Bossle (2015), apesar de trazer interessantes contribuições para o campo da EF, sobretudo no contexto do ensino médio, não aprofunda nas reflexões teóricas acerca do termo "juventude" e sua incidência específica na produção da área. Nesse sentido, acredito que uma nova revisão de literatura pode oferecer outras chaves de leitura para, não apenas compreendermos como o campo da EF brasileira conceitua a juventude, mas também refletir sobre outras possibilidades nesta relação.

Nesse bojo, vale a pena reconhecer os trabalhos desenvolvidos por Vago (2009) e Porelli (2015). Vago (2009) propõe uma EF escolar que reconheça a cultura jovem de seus estudantes e que procure auxiliar na formação cultural desses sujeitos ampliando, inclusive, seu repertório corporal. Porelli (2015) se perguntou se a EF escolar tem feito juventudes dentro do contexto do ensino médio e concluiu que, nesta etapa de ensino, a disciplina contribui para "fazer" uma juventude pautada na ideia de diversidade, reconhecendo o jovem na sua complexidade e na sua capacidade de intervir no mundo pelo movimento.

Minha hipótese é que o campo científico da EF brasileira precisa publicizar de maneira clara as suas percepções sobre a juventude brasileira, fato que se torna necessário para o campo também conseguir responder aos desafios que são colocados pela juventude hodierna. Nesse sentido, o campo da EF pode ganhar seu lugar de fala/intervenção na conceituação/cotidiano das juventude(s).

Para responder a essas problematizações, o presente artigo divide-se em quatro etapas: num primeiro momento, apresenta o debate a respeito da condição juvenil, discutindo a presença dos projetos de escolarização nesse seio. O segundo momento é dedicado a um mapeamento da produção científica do campo da EF brasileira sobre o termo "juventude", fato que contribui para os questionamentos a respeito da importância desta área de conhecimento na vida dos jovens. Por fim, a conclusão. 


\section{PERCEPÇÕES SOBRE A JUVENTUDE CONTEMPORÂNEA: do senso comum à realidade}

Diversos são os discursos existentes que procuram definir sobre "o que é ser jovem". O senso comum, de maneira geral, ainda enxerga a juventude como uma "fase da vida" transitória rumo à idade adulta. Essa percepção carrega consigo uma noção de que as instituições sociais são fundamentais no "cuidado" com os jovens. Ou seja, servem para "auxiliar" suas transições, fazendo com que esta passagem seja ordeira e sem conflitos geracionais. Nesse sentido, a família, o Estado e a escola ganham destaque em relação aos projetos de vida juvenis.

Em contrapartida a este discurso, há aquele que considera a juventude como uma categoria social, histórica e cultural. Assim, a juventude é mais do que simplesmente uma fase da vida e passa a se constituir nos seus diversos projetos, classes e marcadores sociais. A partir desta ideia não faz sentido considerar a juventude como uma categoria homogênea, mas sim pensá-la a partir de diferentes modos de "ser jovem", sobretudo, nas diversas identidades e heterogeneidades.

No seio da ideia da juventude como "fase da vida", nasceram algumas perspectivas importantes. Segundo Groppo (2015) uma das contribuições fundamentais da corrente geracional de juventude é, justamente, pensar na capacidade de renovação social. Tal fato se dá por meio das "experiências" que vão forjando a identidade juvenil. Por exemplo, é a partir das experiências que os jovens têm diante do conhecimento produzido por gerações anteriores que eles são capazes de avaliar tal conhecimento, decidindo se o perpetuam ou se o modificam. Assim, para Manheim (1973), a juventude (enquanto geração) tem o poder de transformação social. Groppo (2015, p. 8), na esteira de Manheim (1973), diz que a juventude enquanto uma fase da vida se caracteriza pelas experiências que vive. Essas experiências acontecem de maneira reflexiva e os jovens, na fase que se encontram, já possuem capacidade de avaliá-las.

Concordo com Groppo (2000, 2015) quando ele afirma que autores como Karl Manheim, Erick Erickson (1987) e os integrantes da escola de Birmingham inauguraram, na Sociologia, o que ficou conhecimento como "teorias críticas sobre as juventudes". Aqui, vale destaque para a corrente classista. Segundo Pais (1993) a corrente classista defende que os jovens pertencem à determinada classe social e tal pertencimento é o que caracteriza sua condição juvenil. Willis (1991), inserido neste debate, pesquisou etnograficamente como grupos de jovens podem se opor (ou não) a cultura escolar. Dois grupos de jovens foram estudados: os "rapazes" e os "ce-de-efes". O primeiro grupo se opõe a cultura escolar e rejeitam tudo que dela advém, inclusive o segundo grupo que, por sua vez, são conformados com os processos que ocorrem dentro da escola. Willis mostra como os "rapazes" tentam, a todo custo, se distanciarem das marcas características da instituição escolar. 
Esse distanciamento se dá pela vestimenta, pela prática do fumo e o consumo de bebidas alcoólicas. Essas características colocam em confronto a cultura escolar e a cultura contra-escolar dos "rapazes".

Para Willis (1991), esses confrontos ocorridos entre a instituição escolar e a cultura contraescolar podem ser entendidos como uma forma de oposição entre o formal (a escola) e o informal (os "rapazes"). A escola se apresenta, então, por meio de estruturas específicas referentes às normas, as práticas pedagógicas e a hierarquia estabelecida dentro dela. Já a cultura contra-escolar se baseia em características que não são promulgadas pela escola. Dentre essas, destacam-se o próprio grupo social. De acordo com Willis (1991, p. 42): “A oposição à escola manifesta-se principalmente na luta por ganhar espaço físico e simbólico da instituição e suas regras e por derrotar aquilo que é percebido como seu principal propósito: fazer você trabalhar".

Além disso, podemos estender as análises de Willis e considerar que, a partir do momento em que a escola se situa como um lugar de oposição à cultura juvenil, ela deixa de ser uma instituição importante na constituição destes jovens, tal qual defende as teorias tradicionais da juventude. Para Feixa (1998), o surgimento de algumas instituições modernas auxiliou na constituição da juventude como uma categoria. Dentre essas instituições destaca-se a escola, que emerge como um espaço de iniciação social, de segregação de idades e de transmissão de conhecimento das gerações anteriores para as gerações mais novas.

Contudo, autores como Bungenstab (2019) e Pais (2005) acreditam que atualmente está ocorrendo um movimento não linear que envolve a tríade família/escola/trabalho e as transições juvenis. Ou seja, na sociedade contemporânea, não é possível mais afirmar que as instituições sociais ainda exercem o maior peso nas trajetórias juvenis. A partir desta análise, os processos de socialização juvenis teriam menos influência das instituições e mais força das escolhas e responsabilidades dos jovens. Diante disso, devemos considerar que a juventude pode ser influenciada por processos de socialização que tem o mercado e o consumo como alicerces, sobretudo, a partir do momento em que se desenvolvem as narrativas que consideram os jovens pela ideia de "protagonismo". Tal ideia é perigosa, uma vez que pode causar o distanciamento do Estado e das políticas públicas para o segmento juvenil.

Por outro lado, refletir sobre esses processos não lineares também significa reconhecer que a juventude pode se relacionar com outras “instituições”. Essas, por sua vez, também podem ajudar na construção de indivíduos mais críticos e emancipados. Nesse sentido, a EF, por meio das práticas corporais, podem se fortalecer como novas "instituições" diante das socializações juvenis? Como o campo científico da EF trata este debate? 


\section{O TERMO “JUVENTUDE" NA PRODUÇÃO DA ÁREA DA EDUCAÇÃO FÍSICA BRASILEIRA}

Foi realizada uma pesquisa bibliográfica com a intenção de compreender como o termo “juventude" é referenciado no campo da EF brasileira no que tange a publicação de artigos científicos. Em relação à pesquisa bibliográfica, Lakatos e Marconi (2003) caracterizam que este tipo de pesquisa abrange toda a bibliografia publicada com relação ao tema de estudo, tendo como finalidade colocar o pesquisador diante do que foi escrito sobre determinado assunto. Logo, Bungenstab $(2019,2020)$ diz que não é apenas realizar uma revisão do que já foi publicado, mas suscitar novos enfoques e propor novas abordagens. Os autores concordam que a revisão de literatura além de contribuir para a compreensão do fenômeno estudado, possibilita a articulação do objetivo pesquisado na tentativa de oportunizar que sejam levantadas novas problemáticas e caminhos para o campo de estudo. De acordo com Lima e Mioto (2007) é comum a confusão entre a pesquisa bibliográfica e a revisão de literatura. Segundo os autores, a revisão de literatura é um pré-requisito para a pesquisa bibliográfica; já esta última se caracteriza como sendo um conjunto de procedimento e busca de soluções sempre levando em conta o objeto estudado.

A partir disto, realizou-se um mapeamento específico das publicações de revistas do campo da EF brasileira com atenção ao debate conceitual sobre o termo "juventude". Na esteira de Bungenstab (2018, p.781), elencamos critérios para a escolha das revistas a serem pesquisadas: 1) revistas que mantém diálogo com o campo das Ciências Humanas; 2) que publicam artigos em português; 3) com estratos Qualis/CAPES diferentes, ou seja: pelo menos uma revista de cada estrato, levando em consideração a heterogeneidade dos periódicos e entendendo que há produção de qualidade em revistas de estratos "inferiores" e, 4) revistas que atualmente tem publicações, pelo menos, trimestrais.

Feito isso, as revistas escolhidas foram: Revista Brasileira de Ciências do Esporte (RBCE); Motrivivência; Revista Pensar a Prática; Revista Movimento e Revista Licere. Na caixa de busca de cada revista foi digitado o termo "juventude". Após isso, deu-se atenção às palavras-chaves e resumos dos textos. Os textos que não fizeram referência aos termos "juventude"; "jovem" e "adolescente" foram descartados. De tal modo, o quadro 1 sinaliza o número de textos achados a partir da busca e o número de textos que, especificamente, discutem assuntos no âmbito da juventude.

Quadro 1 - Artigos que fazem alusão ao termo “juventude” em cada periódico (em números). 


\begin{tabular}{|c|c|c|c|c|c|c|}
\hline Termo/Periódicos & Motrivivência & $\begin{array}{c}\text { Pensar a } \\
\text { Prática }\end{array}$ & $\begin{array}{c}\text { Revista } \\
\text { Movimento }\end{array}$ & RBCE & LICERE & TOTAL \\
\hline $\begin{array}{c}\text { A presença do } \\
\text { termo "juventude" }\end{array}$ & 11 & 27 & 17 & 31 & 26 & 112 \\
\hline $\begin{array}{c}\text { Artigos que } \\
\text { discutem temas } \\
\text { relacionados à } \\
\text { "juventude" }\end{array}$ & 5 & 7 & 12 & 5 & 22 & 51 \\
\hline
\end{tabular}

Fonte: construção do autor

Após a busca, foram mapeados 112 artigos que faziam menção ao termo, contudo, esse número foi reduzido, uma vez que 61 textos, apesar de possuírem o termo, nada discutem no âmbito da juventude. Assim, a análise foi feita a partir de 51 artigos. ${ }^{1}$ Vale a pena destacar o primeiro artigo escrito sobre a temática: publicado no ano de 1996 pela revista Movimento, nele, Uvinha (1996) procurou investigar como o mercado se apropriou e classificou a imagem do "corpo jovem" para angariar consumidores. Nesse sentido, “estar jovem” não significa apenas ter o corpo jovem, mas, também, consumir determinados produtos (como roupas, calçados e bebidas) e realizar determinadas práticas corporais. Já a última publicação, do ano de 2018², é de Antunes e Da Silva (2018) que pesquisaram a presença do esporte na vida de jovens em conflito com a lei. Os autores concluíram que, para esses jovens, o esporte surge como uma prática de lazer que tem como objetivo servir como uma fuga do contexto prisional em que vivem.

A partir da leitura minuciosa de cada artigo percebemos que a juventude é conceituada de maneiras diferentes, contudo, todos os textos se preocupam em estabelecer diálogos entre a juventude e categorias que envolvem o campo da EF. Vale destacar que apenas 15 textos se dedicaram a definir o que acreditam ser "juventude". Eles definem juventude como uma construção social dialética, na qual indivíduos e grupos (re)apropriam-se dos valores, normas e padrões estabelecido pelas instituições (Groppo, 2004, 2009). Também pensam a juventude a partir da noção de "culturas juvenis", entendendo o jovem como sujeito social que carrega múltiplas identidades que não aparecem de forma estanque (Pais, 2009).

Segundo Romera (2009), é preciso considerar cada jovem de forma única, levando em conta que a sociedade atual e seus indivíduos se reinventam a cada momento. Já Nascimento e Marin (2015, p. 346), lançam mão das intepretações de Groppo (2004) para conceituar a juventude como:

Há diferentes formas de vivenciar a condição juvenil derivadas das diferenças sociais, de classe, de gênero, entre outras. Em outras palavras, as juventudes estão vinculadas as condições impostas historicamente, socialmente, culturalmente e economicamente. Podemos então, falar de juventudes no plural, porém distintamente

\footnotetext{
${ }^{1}$ Pela limitação de páginas, torna-se inviável analisar todos os 51 artigos mapeados.

${ }^{2}$ Vale lembrar que a pesquisa foi realizada só até o ano de 2018. Os artigos publicados em 2019 não foram incluídos.
} 
das concepções pós-críticas em que a diversidade de condições juvenis se dá pelo sujeito ser o mediador da relação com a sociedade. Falar de juventudes é estar cientes de que estas estão imersas em um sistema político e econômico marcado por desigualdades e pretensões.

Kanitz (2016, p. 219), por sua vez, considera que o jovem é um ser humano em diálogo com um mundo que tem historicidade e significados: "[...] ele representa um ser singular, que tem uma história, interpreta o mundo, dá-lhe sentido, bem como a posição que ocupa nele, às suas relações com os outros, à sua própria história e a sua singularidade." Nesse mesmo sentido, Bungenstab e Almeida (2016) se ancoram nas discussões feitas por Dayrell (2003) e Pais (1993) para afirmarem que existem diferentes juventudes e os jovens se diferenciam a partir de suas posições sociais, seus locais e suas situações econômicas.

Outro ponto importante é o fato de 36 textos não terem se preocupado em conceituar o termo “juventude". Isso seria suficiente para afirmarmos que o campo da EF brasileira, em sua maioria, não se preocupa com este nível de debate? Como sabemos, a construção teórica sobre a juventude é multidisciplinar e, dela, participam diversas áreas como a sociologia, psicologia, educação e a história. Se a participação do campo da EF brasileira é pequena no que tange aos aportes teóricos, quais são as outras possibilidades de participação neste debate?

Os temas dos artigos mapeados dizem respeito não só a questões relativas ao corpo e ao esporte, mas também se referem às políticas públicas (Bonalume, 2011; Paes e Amaral, 2017; Bungenstab, 2019), ao consumo de drogas (Bertolo e Romera, 2011; Romera, 2014; Romera et al, 2018), as práticas corporais (Leonardo e Scaglia, 2018; Nogueira, 2015), ao corpo (Amgarten Quitzau e Soares, 2010) e mídias digitais (Hack e Pires, 2007). Até o presente momento a Revista Licere foi a que mais produziu sobre a temática estudada: publicou $43 \%$ dos artigos sobre juventude. Tal fato significa, também, que quase a metade dos artigos publicados na área da EF brasileira sobre juventude se dedicam em pesquisar os jovens diante do lazer, já que a revista Licere é dedicada exclusivamente para essa temática. Nesse sentido, Dalben e Góis Júnior (2018, p. 170) analisam as práticas esportivas dos jovens no início do século XX e afirmam que as políticas públicas de lazer objetivavam sistematizar/controlar as práticas juvenis:

[...] Entretanto [...] os projetos de educação das juventudes muitas vezes foram presentes apenas no campo discursivo, o que não significa que foram falsos, e sim que evidenciavam as muitas divisões sociais daqueles contextos urbanos brasileiros em que as práticas eram reapropriadas, ressignificadas e também reproduzidas, pois eram multifacetadas, assim como as juventudes.

Já Nascimento e Marin (2015) destacam que, na atual conjuntura econômica e social, lazer e juventude estão imbricados. Assim, salientam que o lazer, ao mesmo tempo em que liberta o sujeito 
tornando-o mais emancipado, também pode surgir como mercadoria, influenciando os jovens no processo de alienação e fetichização. Ou seja, o jovem, por meio da indústria cultural, pode acabar sendo "domesticado" pelo mercado. No seio deste debate Cruz Junior e Bungenstab (2018) acreditam que o lazer mediado pelas tecnologias digitais surge como importante vetor no protagonismo juvenil, uma vez que possibilita plataformas de sociabilidades e oportuniza novas linguagens e ferramentas criativas para a juventude. Já Kanitz (2016, p. 222) destaca que a corporeidade formada durante as rodas de capoeira fazem com que os jovens moradores de bairros violentos desloquem suas subjetividades para outras esferas.

A Capoeira Angola, como dimensão do campo do lazer, reflete uma das poucas escolhas desses jovens, que poderiam estar em outros ambientes, construindo outras identidades. $\mathrm{O}$ fato de pertencer a um grupo, de criar vínculos, estabelecer redes de relacionamentos, representa uma possibilidade de vencer os perigos cotidianos.

Concordo com Nascimento e Marin (2015) quando eles afirmam que a relação entre a juventude e o lazer projetam novas contradições. Assim, após a análise dos textos publicados, podemos afirmar que, de uma maneira geral, o campo da EF brasileira reconhece que: se a juventude é uma categoria social, ela também pode influenciar e ser influenciada pelos momentos de lazer na sociedade capitalista, seja para ressignificar suas práticas cotidianas ou para reproduzir a lógica atual da sociedade do consumo. Carrano (2003) também vai dizer que as práticas culturais e esportivas de lazer são fundamentais para a compreensão de sociabilidades juvenis e para a constituição de suas múltiplas identidades.

Destas análises, podem-se tecer algumas reflexões a respeito dos impactos que o campo da EF brasileira pode causar diante dos jovens. A EF, por meio dos seus conteúdos e da sua intervenção na realidade, aparenta funcionar como uma espécie de "instituição" que surge, não apenas como momento de passagem, mas, principalmente, como espaço de sociabilização que incidi na condição juvenil, tal qual a escola, a família e o Estado. Fato é que os jovens estabelecem relações dialéticas com seus momentos esportivos, de lazer e, ao passo que influenciam essas práticas, também são influenciados por elas. Nesse sentido, vale a pena perguntar: qual juventude a EF brasileira quer auxiliar a construir?

Corroboro as ideias de Gomes da Silva e Gomes (2008) e de Dos Santos (2015) quando eles salientam a importância de o campo da EF brasileira trabalhar a partir das especificidades das linguagens geradas pelos jovens. Nesse sentido, no espaço formal, a EF escolar apontaria como principal meio de educação; já fora da escola o lazer cumpriria este papel, não apenas de educação "formal”, mas também de educação cidadã e política. De tal modo, claro, a relação entre a EF e a juventude se dá em diferentes universos educativos. 


\section{CONCLUSÃO}

A partir desta revisão de literatura, é possível afirmar que ainda é incipiente a participação do campo científico da EF brasileira no debate sobre a juventude. Contudo, acredito que é importante definir o que é a juventude(s), uma vez que esta ideia irá influenciar no trato que o campo dá a presença das práticas corporais diante dos jovens. Viu-se, nesse sentido, que apenas 15 artigos conceituaram o que entendem por juventude. Se a consideração da juventude permear a noção geracional (fase da vida), as práticas corporais (algumas delas) podem aparecer apenas como momentos de transição, similares àqueles presentes no debate sobre os ritos de passagem (Pais, 2009). De fato, o senso comum parece ainda perpetuar esta noção, fazendo com que os momentos dos jovens com as práticas corporais sejam apenas efêmeros nesta etapa da vida, dentro do contexto escolar e/ou fora dele (lazer). Poderíamos falar, então, de "práticas corporais passageiras"?

É urgente pensar nas práticas corporais juvenis não como ritos passageiros, mas sim como práticas que constituem o jovem e lhe conferem sentido e significado. De tal modo, poderemos assumir um status de "instituição" constituidora da juventude, assim como já é a escola, a família e o trabalho. Aqui, vale a pena considerar as contribuições de Mannheim (1973) a respeito da capacidade de "renovação social" da juventude: tanto o espaço formal como o espaço informal se tornam importantes. Como exemplo, podemos falar sobre as brincadeiras de rua e algumas práticas corporais que têm sua gênese dentro de um recorte temporal determinado, mas que, nem por isso, desaparecem no tempo.

Para além do que concluíram Zilberstein e Bossle (2015), quando os mesmos afirmaram que o termo "juventude" aparece, quase sempre, atrelado a grande área da educação; o presente mapeamento da produção da área nos permite afirmar que, mesmo timidamente, o campo da EF brasileira se interessa em compreender a relação que a juventude estabelece com os mais diversos conteúdos corporais, principalmente, os oriundos dos momentos de lazer. Tal fato ajuda a reforçar a presença dos conteúdos da EF na vida dos jovens. A juventude é uma construção social, histórica e cultural e, se os jovens realmente são sujeitos sociais, eles apresentam transições juvenis complexas. Defendo, portanto, que as práticas corporais podem auxiliar na condição juvenil (como geração e/ou categoria social), uma vez que as experiências oriundas dessas práticas acabam sendo internalizadas pelos jovens, podendo, inclusive, serem reconfiguradas pelos mesmos de maneira dialética. É necessário que, por meio da $\mathrm{EF}$, as práticas corporais sejam promovidas enquanto direito universal para toda a juventude e que essas experiências não sejam pautadas pelo consumo e pela objetivação do corpo. Assim, parafraseando Dayrell (2007), faz mais sentido tentar entender sobre qual 
juventude a EF "faz" (e em que espaço educativo isso ocorre) e menos se perguntar se ela "faz" juventude.

\section{REFERÊNCIAS}

ANTUNES, Sheila.; DA SILVA, Otávio. O esporte na ressocialização de jovens em conflito com a lei - um estudo de caso. Pensar a Prática, v. 21, n. 1, 29 mar. 2018.

AMGARTEN QUITZAU, Evelise; SOARES, Carmen Lúcia. “A força da juventude garante o futuro de um povo": a educação do corpo no Sport Club Germania (1899-1938). Movimento (ESEFID/UFRGS), Porto Alegre, v. 16, n. 3, p. 87-106, maio 2010.

ALVES, Vladimir Zamorano; MELO, Victor Andrade. Um novo barato: surfe e contracultura no Rio de Janeiro dos anos 1970. Revista Brasileira de Ciências do Esporte, Rio de Janeiro, v. 39, n. 1, p. 2-9, 2017.

BERTOLO, Mayara; ROMERA, Liana. Cerveja e publicidade: uma estreita relação entre lazer e consumo. Licere, Belo Horizonte, v. 14, n. 2, p.1, 2011.

BONALUME, Claudia Regina. O paradigma da intersetorialidade nas políticas públicas de esporte e lazer. Licere, v. 14, n.1, Belo Horizonte, 2011.

BUNGENSTAB, Gabriel Carvalho; ALMEIDA, Felipe Quintão de. Práticas corporais nas escolas de ensino médio situadas em Vitória/Espírito Santo. Pensar a Prática, v. 19, n. 1, 31 mar. 2016.

BUNGENSTAB, Gabriel Carvalho. A presença de Anthony Giddens na produção científica da Educação Física brasileira: entre a reflexão e o deslize. Movimento (ESEFID/UFRGS), Porto Alegre, p. 777-788, set. 2018.

BUNGENSTAB, Gabriel Carvalho. Educação Física, ensino médio e juventude: vamos falar sobre crise?. Pensar a Prática, v. 22, 2 ago. 2019.

CARRANO, Paulo Cezar. Juventudes e cidades educadoras. Petrópolis, RJ, Vozes, 2003.

CRUZ JUNIOR, Gilson; BUNGENSTAB, Gabriel Carvalho. Entre o tempo livre e a educação: considerações sobre juventudes, mídias e lazer. Revista Licere, v. 21, n.4, p. 502-528. dez. 2018. Disponível em: https://periodicos.ufmg.br/index.php/licere/article/view/1951. Acesso em: 5 jan. 2019.

DALBEN, André; GÓIS JÚNIOR, Edivaldo. Embates esportivos: o debate entre médicos, educadores e cronistas sobre o esporte e a educação da juventude (rio de janeiro e são paulo, 19151929). Movimento (ESEFID/UFRGS), Porto Alegre, p. 161-172, mar. 2018.

DAYRELL, Juarez. A escola "faz" as juventudes? Reflexões em torno da socialização juvenil. Educ. Soc., Campinas , v. 28, n. 100, p. 1105-1128, Oct. 2007.

DOS SANTOS, Marcel Ivan. Escola, Educação Física e juventude: caminhos para cidadania. Motrivivência, Florianópolis, v. 27, n. 46, p. 154-170, nov. 2015. 
ERICKSON, Erik H. Sociedad y adolescencia. México: Siglo xxi, 1987.

FABRI, Eliane Isabel; ROSSI, Fernanda; FERREIRA, Lilian Aparecida. Episódios marcantes das aulas de Educação Física: valorizando as experiências dos alunos por meio de narrativas.

Movimento (ESEFID/UFRGS), Porto Alegre, p. 583-596, jan. 2016.

FEIXA, Carles. De jóvenes, bandas y tribus. Barcelona: Editora Ariel. 1998.

FORACCHI, Marialice. A juventude na sociedade moderna. São Paulo: Livraria Pioneira, Editora da Universidade de São Paulo, 1972.

GROPPO, Luis Antonio. Juventude: ensaios sobre sociologia e história das juventudes modernas. Rio de Janeiro: Difel, 2000.

GROPPO, Luis Antonio. A emergência da juventude e do lazer como categorias socioculturais da modernidade. Licere, Belo Horizonte, v. 5, n. 1, p. 73-82, 2002.

GROPPO, Luis Antonio. Dialética das juventudes modernas e contemporâneas. Revista de Educação do Cogeime, n.25, p.9-22, Dez. 2004.

GROPPO, Luis Antonio. O funcionalismo e a tese da moratória social na análise das rebeldias juvenis. Estudos de Sociologia, 14 (26), 37-50. 2009.

GROPPO, Luis Antonio. Teorias críticas da juventude: geração, moratória social e subculturas juvenis. Em Tese, 12(1), 4-33. 2015.

KANITZ, Roberto Camargo Malcher. Os Angoleiros da Favela: Um olhar sobre Lazer, Juventude e Violência. Revista Licere, v. 19, n.2, p. 199-225. Jun. 2016.

KUNZ, Elenor. Unidade Didática 5 - Práticas Didáticas para um "Conhecimento de Si” de

Crianças e Jovens na Educação Física . In: KUNZ, Elenor. Didática da Educação Física 2. 2. ed. Ijuí: Unijuí, 2004, cap. 1, p. 15-52.

HACK, Cassia; PIRES, Giovani. Lazer e mídia no cotidiano das culturas juvenis. Revista Licere, 10(1), 1-22. 2007.

LEONARDO, Lucas; SCAGLIA, Alcides José. A avaliação de competições esportivas de jovens: definição de categorias e aplicações ao handebol. Movimento (ESEFID/UFRGS), Porto Alegre, p. 875-888, set. 2018.

LIMA, Telma Cristiane Sasso de; MIOTO, Regina Célia Tamaso. Procedimentos metodológicos na construção do conhecimento científico: a pesquisa bibliográfica. Rev. katálysis, Florianópolis, v. 10, n. spe, p. 37-45, 2007 .

MANNHEIM, Karl. Diagnóstico de nosso tempo. 3.edição. Rio de Janeiro: Zahar, 1973.

NASCIMENTO, Thaine Bonaldo do; MARIN, Elizara Carolina. Lazer e juventude: relações de segurança e risco em danceterias. Revista Licere; v.18, n. 4, p. 341-363, 2015. 
NOGUEIRA, Quefren Weld Cardozo. Equipes esportivas no colégio arquidiocesano sagrado coração de jesus: anotações sobre a experiência de jogo como formação. Movimento (ESEFID/UFRGS), Porto Alegre, p. 731-742, jun. 2015.

PAES, Viviane Ribeiro; AMARAL, Silvia Cristina Franco. Políticas públicas de esporte educacional em são paulo: impactos dos jogos olímpicos de 2016. Movimento (ESEFID/UFRGS), Porto Alegre, p. 715-728, jun. 2017.

PAIS, José Machado. Culturas juvenis. Lisboa: Imprensa Nacional Casa da Moeda, 1993.

PAIS, José Machado. Jovens e cidadania. Sociologia, Problemas e Práticas, 49(1), 53-70, 2005.

PAIS, José Machado. A juventude como fase de vida: dos ritos de passagem aos ritos de impasse. Saúde Soc ;v.18, n.3, p. 371-381, 2009.

PORELLI, Beatriz Gasquez. Sentidos e significados da Educação Física para a(s) juventude(s). Dissertação (Mestrado em Educação Física) Faculdade de Educação Física - Universidade Estadual de Campinas, 2015.

ROMERA, Liana Abrão. As drogas e os cenários de lazer. Licere, 17(3), 303-317, 2014.

ROMERA, Liana Abrão et al. Tempo livre e uso de álcool e outras drogas: estudo comparativo entre estudantes universitários do brasil e portugal. Movimento (ESEFID/UFRGS), Porto Alegre, p. 765-776, set. 2018.

GOMES DA SILVA, Pierre Normando.; GOMES, Eunice Simões Lins. Eternamente jovem: corpo malhado, ficção televisual e imaginário. Pensar a Prática, v. 11, n. 2, p. 197 - 207, 15 ago. 2008.

UVINHA Ricardo Ricci. O corpo-imagem jovem e o fenômeno do consumo. Movimento v.3, p.49$51,1996$.

VAGO, Tarcísio Mauro. Pensar a educação física na escola: para uma formação cultural da infância e da juventude. Cadernos de Formação RBCE, p. 25-42, set. 2009.

WILLIS, Paul. Aprendendo a ser trabalhador: escola, resistência e reprodução social. Porto Alegre: Artes Médicas, 1991.

ZYLBERBERG, Tatiana Passos; BEZERRA, Fabrício Leomar Lima. Juventude e internet:

possibilidades de “criar” Educação Física. Atos de Pesquisa em Educação, Blumenau, v. 8, n. 1, p. 182-208, jan./abr. 2013.

ZILBERSTEIN, Jaqueline; BOSSLE, Fabiano. A produção sobre juventude em periódicos da Educação e Educação Física. Motrivivência, Florianópolis, v. 27, n. 46, p. 214-229, nov. 2015. 


\section{NOTAS DE AUTOR}

\section{AGRADECIMENTOS}

Não se aplica.

CONTRIBUIÇÃO DE AUTORIA

Não se aplica.

\section{FINANCIAMENTO}

Não se aplica.

\section{CONSENTIMENTO DE USO DE IMAGEM}

Não se aplica.

\section{APROVAÇÃO DE COMITÊ DE ÉTICA EM PESQUISA}

Não se aplica.

\section{CONFLITO DE INTERESSES}

Não se aplica.

\section{LICENÇA DE USO}

Os autores cedem à Motrivivência - ISSN 2175-8042 os direitos exclusivos de primeira publicação, com o trabalho simultaneamente licenciado sob a Licença Creative Commons Attribution Non-Comercial ShareAlike (CC BY-NC SA) 4.0 International. Esta licença permite que terceiros remixem, adaptem e criem a partir do trabalho publicado, desde que para fins não comerciais, atribuindo o devido crédito de autoria e publicação inicial neste periódico desde que adotem a mesma licença, compartilhar igual. Os autores têm autorização para assumir contratos adicionais separadamente, para distribuição não exclusiva da versão do trabalho publicada neste periódico (ex.: publicar em repositório institucional, em site pessoal, publicar uma tradução, ou como capítulo de livro), com reconhecimento de autoria e publicação inicial neste periódico, desde que para fins não comerciais e compartilhar com a mesma licença.

\section{PUBLISHER}

Universidade Federal de Santa Catarina. Programa de Pós-Graduação em Educação Física. LaboMídia - Laboratório e Observatório da Mídia Esportiva. Publicado no Portal de Periódicos UFSC. As ideias expressadas neste artigo são de responsabilidade de seus autores, não representando, necessariamente, a opinião dos editores ou da universidade.

\section{EDITORES}

Mauricio Roberto da Silva, Giovani De Lorenzi Pires, Rogério Santos Pereira

\section{HISTÓRICO}

Recebido em: 20 de setembro de 2019.

Aprovado em: 01 de dezembro de 2019. 